\title{
Psychosocial aspects of changes during adolescence among school going adolescent Indian girls
}

\author{
Shweta Sinha, Jyoti Nath Modi*
}

\begin{abstract}
Department of Obstetrics \& Gynaecology, People's College of Medical Sciences \& Research Centre, Bhopal, Madhya Pradesh, India
\end{abstract}

Received: 28 April 2014

Accepted: 4 May 2014

*Correspondence:

Dr. Jyoti Nath Modi,

E-mail: modijn@gmail.com

(C) 2014 Sinha S et al. This is an open-access article distributed under the terms of the Creative Commons Attribution Non-Commercial License, which permits unrestricted non-commercial use, distribution, and reproduction in any medium, provided the original work is properly cited.

\begin{abstract}
Background: Physical as well as psychological changes during adolescence create a state of physiological stress that must be coped with. This study was undertaken to study the psychosocial aspects of changes associated with adolescence among school going girls.

Methods: A predesigned questionnaire was administered to students of class VI to XII prior to a talk on "Adolescent health' in two urban schools of Bhopal. The questions were directed at understanding the psychosocial aspects of behavior among the girls during adolescence while they cope with changes of adolescence.

Results: A total of 414 schoolgirls from classes VI-XII participated in the study. Their mean age was 14.4years [SD 2.01; Range 10-18 years]. Of them, 277 reported having attained menarche, the mean age at menarche being 12.7 years [SD 1.52]. Almost $63 \%$ of girls had knowledge about menstruation before attaining menarche. Majority of them had learned about it from their mother $(41 \%)$. Nearly one third $(30.6 \%)$ of girls were not comfortable with the bodily changes of adolescence; $41 \%$ reported feeling anxious and $26.4 \%$ reported suffering from low self-esteem. Excessive irritability was reported by $47 \%$ of girls; undue anger by $51.4 \%$, and $34.7 \%$ felt uncomfortable interacting with people. One third of girls had frequent arguments with parents. Almost $80 \%$ of girls found their parents supportive.

Conclusions: A good proportion of adolescent girls appear to be in need for counseling and support for optimally coping with the bodily as well as psychological changes of adolescence. This preliminary study unveils the need for more widespread and regular Adolescent School health programs for increasing awareness and support services.
\end{abstract}

Keywords: Adolescents, School-going girls, Psychosocial aspects, Indian

\section{INTRODUCTION}

Health of adolescent girls determines the health of future generations. The WHO defines adolescents as individuals in the age group 10-19 years. ${ }^{1}$ Adolescence is a period of many hormone based complex changes in the body and mind leading to emotional, physical and social maturation, so as to prepare the individual for functional independence in adult life. This transition period from childhood to adulthood creates a state of turmoil and stress that makes the adolescents vulnerable to many kinds of problems such as psychosocial, general and reproductive health related or sexuality related issues. ${ }^{2}$

The term 'psychosocial' refers to the interplay between the biological, physiological, emotional, cognitive, social, environmental and the maturational factors. Each of these factors should be considered when the problems and the needs of the adolescents are evaluated. ${ }^{3}$ Psychological changes occur largely because the way adolescents see themselves changes dramatically. Simultaneously, there is also a change in the way other people treat them. While 
adolescents cope with the bodily transformations, they are also trying to establish their own system of beliefs, values, life goals and an independent identity. They constantly appraise themselves and hence may become self-conscious. Some of the behavioral manifestations of these psychosocial changes are irritability, anger, emotional instability, depression, awkwardness in interpersonal interactions, and varied degree of selfesteem,

It is important to look for these behavioral issues so that appropriate supportive measures may be instituted and smooth transition to adulthood is facilitated. This study was undertaken to assess the extent of psychosocial coping by adolescent girls in urban schools.

\section{METHODS}

The present study is a school based cross sectional study carried out among girls of class VI to XII in two urban schools of Bhopal. A predesigned, peer-validated written questionnaire was administered to students prior to a talk on 'Adolescent health' in the two schools. Both schools were English medium schools and the questionnaire was in English language. The items in the questionnaire were directed at understanding the psychosocial adjustment and coping among the adolescent girls. They were briefed about the items of the questionnaire and were reassured of anonymity as well as freedom of not participating in the study. It was not compulsory for them to respond to all items or to mention their name. They were allowed to ask clarifying questions.

Descriptive statistics in form of range, standard deviation and percentage frequency has been used to describe the observations.

\section{RESULTS}

A total of 414 schoolgirls from classes VI-XII of two urban schools of Bhopal participated in the study. Their mean age was 14.42 years [Range 10-18 years; SD 2.01]. Of these, 277 reported as having attained menarche, mean age at menarche being12.66 years [SD 1.52].

All participants did not respond to all items on the questionnaire. The average response rate for the various items in the questionnaire was $88.6 \%$. The analysis is therefore presented as percentage of responders to that particular item on the questionnaire. Item-wise responses are summarized in Table 1.

Two hundred and eighty three girls responded to the question on whether they were aware of menstruation prior to menarche. About $63 \%$ of these girls had knowledge regarding menstruation prior to menarche (this included some girls who were yet to attain menarche). A total of 327 girls responded to the question on the source of information regarding menstruation. Overall, most of the girls had learnt about menses from their mothers $(41 \%)$, friends $(21 \%)$ or sister $(14 \%)$ and a few from books $(4.9 \%)$, Internet $(8 \%)$ or other family members (Figure 1). However, the counseling regarding menstrual hygiene was done for most of them by their mothers $(265 / 316 ; 83.9 \%)$ followed by friends $(6.3 \%)$.

Table 1: Frequency of responses to the various items in the questionnaire.

\begin{tabular}{|c|c|c|c|c|}
\hline \multirow{2}{*}{$\begin{array}{l}\text { Psycho-social } \\
\text { aspects as asked } \\
\text { in questionnaire }\end{array}$} & \multirow{2}{*}{$\begin{array}{l}\text { No. of } \\
\text { respon } \\
\text {-dents } \\
\text { (n) }\end{array}$} & \multicolumn{3}{|c|}{ Frequency of responses } \\
\hline & & No & Yes & Unsure \\
\hline $\begin{array}{l}\text { Comfortable with } \\
\text { bodily changes of } \\
\text { adolescence }\end{array}$ & 356 & $\begin{array}{l}109 \\
(30.6 \%)\end{array}$ & $\begin{array}{l}186 \\
(52.2 \%)\end{array}$ & $\begin{array}{l}61 \\
(17.3 \%)\end{array}$ \\
\hline $\begin{array}{l}\text { Get too } \\
\text { emotional and } \\
\text { cry easily }\end{array}$ & 392 & $\begin{array}{l}184 \\
(46.9 \%)\end{array}$ & $\begin{array}{l}185 \\
(47.1 \%)\end{array}$ & $\begin{array}{l}23 \\
(5.9 \%)\end{array}$ \\
\hline $\begin{array}{l}\text { Suffer from low } \\
\text { self-esteem }\end{array}$ & 367 & $\begin{array}{l}221 \\
(60.2 \%)\end{array}$ & $\begin{array}{l}97 \\
(26.4 \%)\end{array}$ & $\begin{array}{l}49 \\
(13.3 \%)\end{array}$ \\
\hline $\begin{array}{l}\text { Very worried / } \\
\text { anxious most of } \\
\text { the time }\end{array}$ & 378 & $\begin{array}{l}181 \\
(47.8 \%)\end{array}$ & $\begin{array}{l}153 \\
(40.5 \%)\end{array}$ & $\begin{array}{l}44 \\
(11.6 \%)\end{array}$ \\
\hline $\begin{array}{l}\text { Uncomfortable } \\
\text { interacting with } \\
\text { people }\end{array}$ & 374 & $\begin{array}{l}196 \\
(52.4 \%)\end{array}$ & $\begin{array}{l}130 \\
(34.8 \%)\end{array}$ & $\begin{array}{l}48 \\
(12.8 \%)\end{array}$ \\
\hline Irritable often & 375 & $\begin{array}{l}155 \\
(41.3 \%)\end{array}$ & $\begin{array}{l}176 \\
(46.9 \%)\end{array}$ & $\begin{array}{l}44 \\
(11.7 \%)\end{array}$ \\
\hline Get angry often & 377 & $\begin{array}{l}150 \\
(39.8 \%)\end{array}$ & $\begin{array}{l}194 \\
(51.5 \%)\end{array}$ & $\begin{array}{l}33 \\
(8.8 \%)\end{array}$ \\
\hline Pick fights often & 374 & $\begin{array}{l}276 \\
(73.8 \%)\end{array}$ & $\begin{array}{l}62 \\
(16.6 \%)\end{array}$ & $\begin{array}{l}36 \\
(9.6 \%)\end{array}$ \\
\hline $\begin{array}{l}\text { Have frequent } \\
\text { arguments with } \\
\text { parents }\end{array}$ & 376 & $\begin{array}{l}228 \\
(60.6 \%)\end{array}$ & $\begin{array}{l}113 \\
(30.1 \%)\end{array}$ & $\begin{array}{l}35 \\
(9.3 \%)\end{array}$ \\
\hline $\begin{array}{l}\text { Feel poorly } \\
\text { understood by } \\
\text { family }\end{array}$ & 377 & $\begin{array}{l}249 \\
(66.4 \%)\end{array}$ & $\begin{array}{l}99 \\
(26.3 \%)\end{array}$ & $\begin{array}{l}29 \\
(7.7 \%)\end{array}$ \\
\hline $\begin{array}{l}\text { Find your parents } \\
\text { supportive }\end{array}$ & 384 & $\begin{array}{l}52 \\
(13.5 \%)\end{array}$ & $\begin{array}{l}309 \\
(80.5 \%)\end{array}$ & $\begin{array}{l}23 \\
(6 \%)\end{array}$ \\
\hline
\end{tabular}

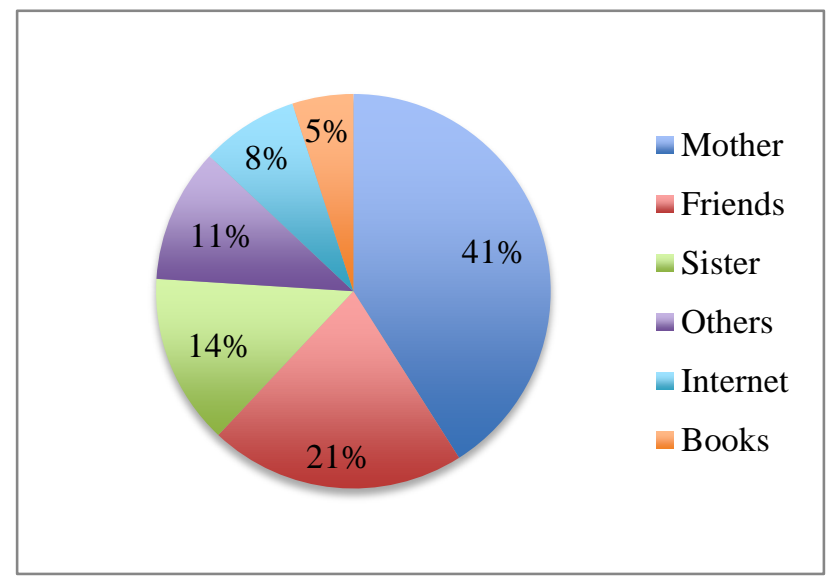

Figure 1: Source of information regarding menses and menstrual hygiene. 
A total of 356 girls responded to the question on whether they were comfortable with the bodily changes of adolescence. About one third of them (30.6\%) were not comfortable with the bodily changes while almost half of them $(52.2 \%)$ were comfortable. The remaining girls were unsure about how they felt.

A total of 392 girls responded to the item on emotional instability and whether they would cry easily. Of these, $47.1 \%$ felt that they had become very emotional and would cry easily and almost a similar number of girls denied such behavior while $5.9 \%$ felt unsure about it.

About $41 \%$ of responders (153/378) reported a feeling of anxiety while $48 \%$ denied any such feeling. Of 367 responders, $26 \%$ reported suffering from low self-esteem while $60 \%$ did not feel so. Figure 2 shows the psychosocial characteristics of the study participants as percentage responses to items in the questionnaire.

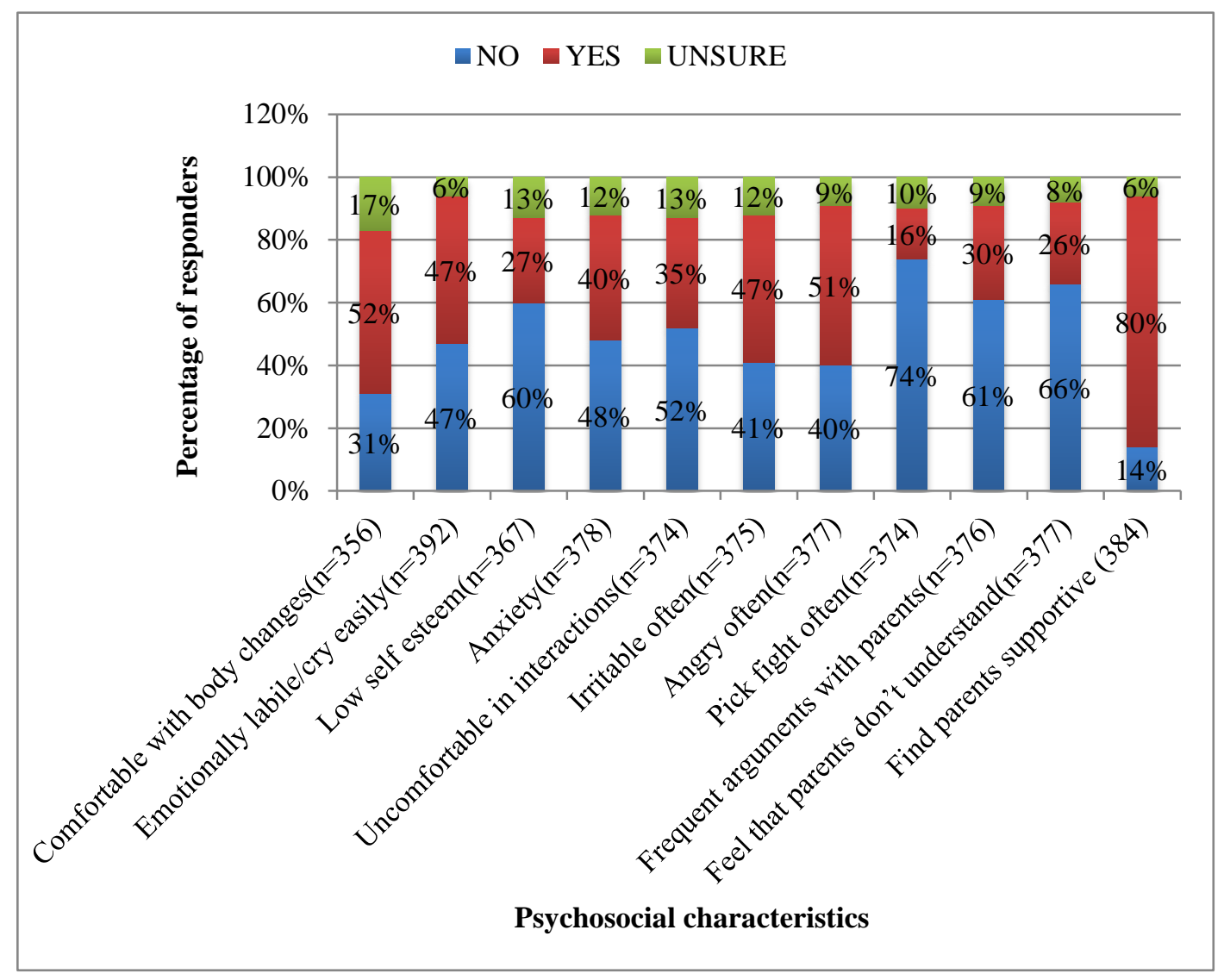

Figure 2: Psychosocial characteristics of school-going adolescent girls represented as percentage of responses to items on the questionnaire.

As regards social and interpersonal behavior, about $34.8 \%$ (130/374) felt uncomfortable while interacting with people while $52 \%$ faced no such problem. Nearly $47 \%$ of girls (176/375) reported excess irritability, and $51.4 \%$ girls (194/377) reported frequent anger. However, only $16.6 \%(62 / 374)$ reported picking frequent fights with people.

With regards to interaction with parents, $30 \%$ of girls (113/376) reported having frequent arguments with parents. A good majority $(81 \% ; 309 / 384)$ found their parents supportive during this phase of transition. A much smaller proportion $(26 \%$; 99/377) felt that their family did not understand them well.
Most of the girls (44\%) reported sharing their problems with their mothers followed by those who shared with friends $(25 \%)$ or sisters $(7 \%)$.

\section{DISCUSSION}

With increasing westernization of our culture and living, we are likely to follow the trends of adolescent health issues on a similar track. The mean age at menarche was found to be 12.7 years in the present study, which is a little lower than that reported by earlier studies. ${ }^{4-6}$ It has been observed that the age at menarche has been decreasing generally in many countries with a mean age 
at menarche ranging from 12 to 13 years in the majority of developed countries. ${ }^{7}$

In our study about $63 \%$ girls were aware of menstruation process before attaining menarche. This rate is higher than that reported by Nair et al in their study on girls from schools of rural area of Delhi. ${ }^{4}$ They reported that nearly $46 \%$ of girls who had attained menarche and $29 \%$ of pre-pubertal girls had prior knowledge about menses. An ICMR survey from urban areas of Delhi reported awareness of menstruation to about $66 \% .^{6}$ Dube et al. in 2012, from Jaipur reported that $33 \%$ of urban adolescent girls and $62 \%$ of rural adolescent girls in the age 15-19 years had prior information regarding menses. ${ }^{8}$ This wide variation and conflicting reports on awareness level may be due to geographic, cultural, socioeconomic and literacy differences between study groups of various studies.

Most of girls in our study had learnt about menstruation from mother $(41 \%)$ followed by friends $(21 \%)$, sisters (14\%), Internet (8\%) and books (5\%). Nair et al in 2007, also report a similar pattern of source of information. They found that the mothers $(41 \%)$ were the most common source of information about menstruation, followed by elder sisters $(22.4 \%)$, friends $(21 \%)$, relatives $(6.7 \%)$, television $(4.4 \%)$, books $(3.3 \%)$, and doctors $(1.1 \%){ }^{4}$ The study from Jaipur by Dube at al. reported that $41 \%$ urban and $56 \%$ of rural respondents received information about menarche from their relatives, whereas $30 \%$ urban and 24\% rural girls from friends. $29 \%$ urban and $20 \%$ rural respondents got the information from media like T.V., radio and magazines. ${ }^{8}$

Many researchers have studied psychosocial and psychiatric problems among adolescents. Mishra et al reported a clinico-social study of psychiatric morbidity among adolescent school going girls aged 12-18 years of Delhi in 2001. ${ }^{9}$ They found that $13.76 \%$ girls had psychiatric morbidity, the commonest problem being anxiety/depression (10\%). They also found that the primary factors associated with psychiatric morbidity were linked to the girls' relationship with parents (relationship with father; perception of mother's love for her), and her perception of self in terms of appearance. It is also observed in another study that adolescents lack awareness and correct information about psychological changes of adolescence. ${ }^{10}$

In the present study, nearly $41 \%$ girls reported feeling anxious. Other behavioral aspects of girls in the present study were their feeling emotionally labile and crying easily (47\%), irritable (47\%), and getting angry often (52\%). These higher reporting rates in our study are possibly due to the fact that these are self-reported feelings rather than measurements of psychiatric morbidity using a standard instrument. It is encouraging to note that a good majority of participants $(80 \%)$ in our study felt that their parents were supportive and most relied on their family members for discussing problems.
More than half (52\%) of respondents in our study were not comfortable with the bodily changes of adolescence and $26 \%$ reported suffering from low self-esteem. Nearly one third of girls in the present study felt uncomfortable interacting with people. Altintas et al., in 2013 found that body mass index and physical activity play the most important role in body related perception and self-esteem of adolescents. ${ }^{11}$ This suggests that besides a need for counseling and preparing adolescents for these changes and transitions, it is equally important to encourage physical activity and maintenance of normal weight.

\section{CONCLUSIONS}

A good proportion of adolescent girls appear to be in need for counseling and support for coping with the bodily as well as psychological changes of adolescence. This survey unveils the need for more widespread and regular adolescent school health programs in order to recognize problems early and provide solutions accordingly.

\section{ACKNOWLEDGEMENTS}

We gratefully acknowledge the students for their participation, the school administration granting us due permission to carry out the study and the help provided by Dr. Pooja Iyer in conducting the health talk in schools.

Funding: No funding sources Conflict of interest: None declared

Ethical approval: The study was approved by the institutional regulatory body

\section{REFERENCES}

1. World Health Organization. Adolescent friendly health services: an agenda for change. In: WHO, eds. WHO Agenda. Geneva: World Health Organization; 2002: 5 .

2. Agrawal S, Fatma A, Singh CM. A study of knowledge and attitude of adolescent girls towards reproductive health and related problems. Indian $\mathbf{J}$ Prev Soc Med. 2007;38(1, 2):36-41.

3. Pratt HD, Principles of psychosocial assessment of adolescents. Indian J Pediatr. 2003;70(10):775-80.

4. Nair P, Grover LV. Awareness and practices of menstruation and pubertal changes amongst unmarried female adolescent in a rural area of East Delhi. Ind J Comm Med. 2007;32(2):156-7.

5. Shiela, W, Malathy K, Premila, S. Menstrual and gynaecological disorders in 500 school girls in Madras city. J Obstet Gynaecol India. 1993;43:9405 .

6. Grover VL. Final report on a study of reproductive health awareness and sexual behaviour among adolescents in Delhi. In: Grover VL, eds. ICMR Report. Delhi: Report submitted to ICMR; 1998. 
7. Padez, Rocha M A. Age at menarche in Coimbra (Portugal) school girls: a note on secular changes. Ann Hum Biol. 2003;30(5):622-32.

8. Dube S, Sharma K. Knowledge, attitude and practice regarding reproductive health among urban and rural girls: a comparative study. Ethno Med. 2012;6(2):8594.

9. Mishra A, Sharma AK. A clinico-social study of psychiatric morbidity in 12 to 18 years school going girls in urban Delhi. Indian $\mathbf{J}$ Comm Med. 2001;26:71-5.
10. Jain RB, Kumar A, Khanna P. Assessment of selfawareness among rural adolescents: a cross-sectional study. Indian J Endocrinol Metab. 2013;17:S367-72.

11. Altintas A, Asci FH, Kin-Isler A, Guven-Karahan B, Kelecek S, YIlmaz A, Kara FM. The role of physical activity, body mass index and maturity status in body-related perceptions and self-esteem of adolescents. Ann Hum Biol. 2013:1-8.

DOI: $10.5455 / 2320-1770$. ijrcog20140625

Cite this article as: Sinha S, Modi JN. Psychosocial aspects of changes during adolescence among school going adolescent Indian girls. Int J Reprod Contracept Obstet Gynecol 2014;3:409-13. 